\title{
Embedded Retaining Wall Design and Performance Monitoring for Deep Excavation in Geological Conditions of Qatar
}

\author{
Muhammad Humza \\ Muhammad.humza@parsons.com \\ Parsons International Limited, Doha, Qatar \\ Ghulam Sarwar \\ Sarwar.Ghulam@parsons.com \\ Parsons International Limited, Doha, Qatar \\ Majid Naeem \\ Majid.naeem@ammico.biz \\ Ammico Contracting Company, Doha, Qatar \\ Gorkem Dora \\ Gorkem.dora@ammico.biz \\ Ammico Contracting Company, Doha, Qatar
}

\begin{abstract}
Embedded retaining walls such as diaphragm walls and secant bored pile walls have become viable water-tight earth retaining and stabilizing systems for deep excavation in urban areas. In this article, the design aspects of a diaphragm wall are presented, and its performance is assessed and comparison of predicted wall movements with the observed behavior is discussed. The geotechnical analysis and design of retaining system was performed by finite element analysis using PLAXIS with linear elastic perfectly plastic constitutive model. Structural calculations for the support system were done using structural program Staad Pro. A monitoring program was adopted to monitor the performance of the designed retaining system. Design methodology and discussion on understanding of performance monitoring presented in this paper provides a reference for the future design and safe economical construction of similar structures in geological conditions of Qatar. It also provides basis for the potential refinement of the monitoring techniques of embedded retaining walls in Qatar.
\end{abstract}

Keywords: Deep excavation; Embedded retaining wall; Finite Element analysis; Performance monitoring

\section{INTRODUCTION}

Embedded retaining walls such as diaphragm walls and secant bored pile walls have become viable water-tight earth retaining and stabilizing systems for deep excavation in urban areas. The advantage of diaphragm wall over the other retaining walls is its use as temporary retention system as well as permanent wall and foundation system. The advantage of a diaphragm, wall over a secant pile wall is the reduced number of joints in the wall which ultimately improves the wall water tightness. Diaphragm walls are installed using trench cutter in the rock formations of Qatar in a series of discrete panels typically ranging in length from $2.8 \mathrm{~m}$ to $7.0 \mathrm{~m}$. Adnan et. al. (2019) presented the case study to show diaphragm wall performance supported by steel struts in rock formations of Qatar. The focus of this paper is on performance monitoring and techniques being used for the monitoring of braced excavations in Qatar. 


\section{PROJECT BACKGROUND}

The project presented for this case study was in Lusail area of Qatar. The $17.5 \mathrm{~m}$ deep excavation was carried out for the construction of four (04) basements. No critical structures were present adjacent to the excavation except asphalt roads; however, the site was about $140 \mathrm{~m}$ away from the Arabian Gulf as shown in Figure 1. Therefore, diaphragm wall was used as a water-tight earth retaining system in the proximity of sea. The retaining system was supported by steel struts due to regulations of statutory authority since the installation of ground anchors is prohibited.

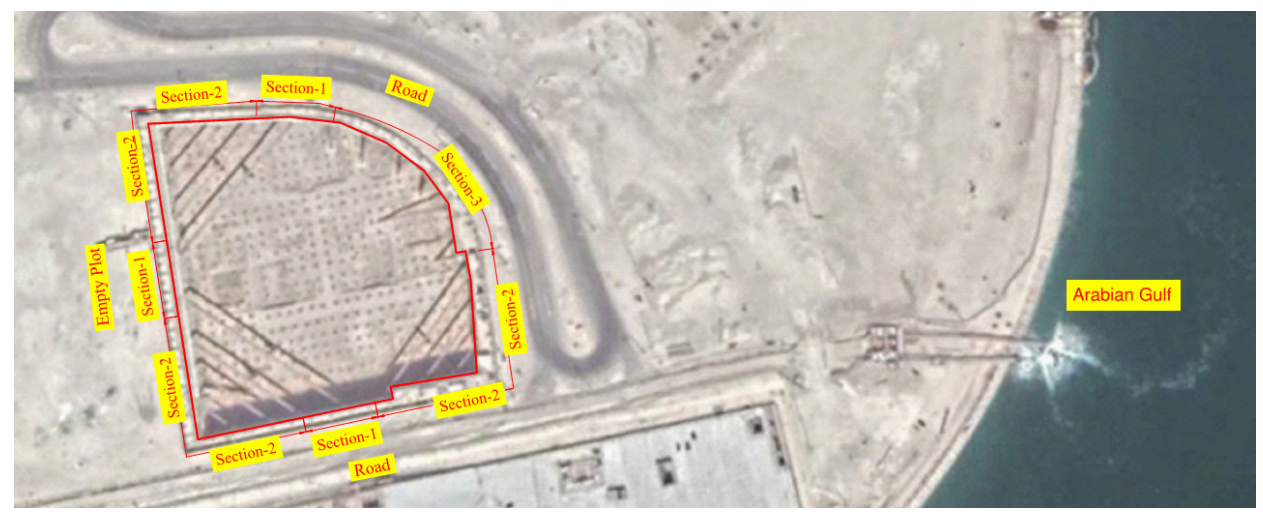

Figure 1: Project layout plan

\section{GEOLOGICAL CONDITIONS}

At depths relative to civil engineering, the geological formations in Qatar peninsula belong to Palaeogene to Quaternary age (Cavellier et al., 1970; Fourniadis, 2010). Within Doha, mainly made ground and residual soils are present on or close to the ground surface, however, marine sediments are found at coastline of Qatar. The main geological formations, in stratigraphic succession, are upper Dammam formation (Simsima Limestone member), Lower Dammam formation (Dukhan Limestone and Midra Shale member) and Rus Formation. The rock units of these formations are mainly comprised of limestones, shales, siltstones, claystones, marls and gypsum. The Simsima Limestone member is present over $80 \%$ of the land surface of Qatar. Therefore, most deep excavations, within Doha, have been carried out in Simsima Limestone member. It has been the main founding stratum for most structures due to its presence at shallower depths, thickness and its geotechnical properties. Nevertheless, there is a spatial variance in the thickness and geological characteristics of subsurface formations owing to depositional factors, in particular, near coastlines of Qatar where thick marine deposits are encountered. Therefore, deep excavations and foundations require special attention in the design and method of construction in the marine deposits. For this project, geotechnical parameters were derived from traditional site investigation and laboratory testing program and the derived design parameters are summarized in Table 1. 
Table 1: Geotechnical design parameters for FE analysis

\begin{tabular}{|c|c|c|c|c|c|}
\hline Material & $\begin{array}{c}\text { Elevation } \\
\text { (m QNHD) }\end{array}$ & $\begin{array}{l}\text { Unit Weight } \\
\left(\mathbf{k N} / \mathbf{m}^{3}\right)\end{array}$ & $\begin{array}{c}\text { Cohesion } \\
(\mathrm{kPa})\end{array}$ & $\begin{array}{c}\text { Friction Angle } \\
\text { (degrees) }\end{array}$ & $\begin{array}{c}\text { Modulus, E } \\
\text { (MPa) }\end{array}$ \\
\hline Quaternary Deposits & 2.65 to 1.95 & 18 & 0 & 35 & 25 \\
\hline Weathered Simsima Limestone & 1.95 to 0.65 & 22 & 95 & 40 & 350 \\
\hline Simsima Limestone & 0.65 to -10.55 & 24 & 95 & 45 & 350 \\
\hline Rus Formation (Decomposed) & -10.55 to -24.35 & 21 & 0 & 37 & 120 \\
\hline Rus Formation & -24.35 to bottom & 22 & 55 & 24 & 180 \\
\hline
\end{tabular}

\section{DESIGN METHODOLOGY}

Finite Element Method (FEM) using 2D PLAXIS was used to analyze the complexity of the interaction between the ground and the retaining structure and to design a retaining structure in detail before construction. PLAXIS is a two-dimensional (plain strain) finite element program, specifically developed for the analysis of deformation and stability in geotechnical engineering problems. The analyses were performed using linear elastic-perfectly plastic Mohr-Coulomb (MC) constitutive model with effective stress parameters. Though, soil response to loading is nonlinear, inelastic and highly dependent on the magnitude of stress, the linear elastic model was used for rock formation because of its simplicity and rock deformation modulus can easily be determined through lab and field testing that is used as primary loading stiffness parameter in MC model.

Three design sections were analyzed according to varying excavation geometry as shown in Figure 1. The finite element models analyzed for section 1, section 2 and section 3 are presented in the Figure 2 . The $0.8 \mathrm{~m}$ thick diaphragm wall was modelled as a plate element. Surcharge load of $20 \mathrm{kPa}$ was considered for all sections. Diagonal steel struts at section 1 and section 2 modelled as fixed-end anchor and installed at $6.15 \mathrm{~m}$ below the existing ground with $10 \mathrm{~m}$ spacing between two struts. Diaphragm wall at section 3 supported by inclined steel struts. Inclined steel strut was modelled as nodeto-node anchor. The modelled construction sequence was followed at site during the construction.

For section 3 (Figure 2b), the supporting piles were installed at $6.15 \mathrm{~m}$ below the existing ground level. Excavation was then carried out leaving the rock berm against the wall in section 3. The inclined struts were installed in a way that one end of inclined steel struts rest on concrete Waller beam whilst other end on concrete square cap supported by a pile by creating a slot inside the berm.

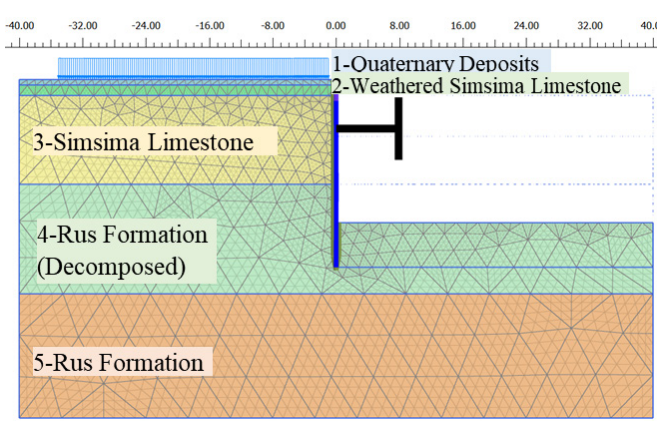

a) Section $1 \& 2$

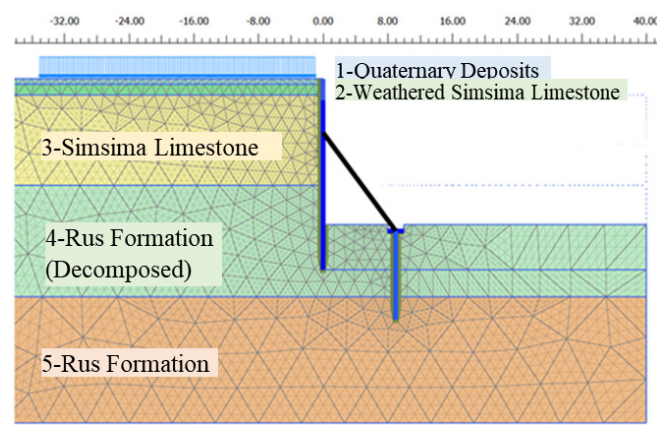

b) Section 3

Figure 2: Finite Element models (a) Section $1 \& 2$ and (b) Section 3 
RC Waller beam with strut spacing modelled in STAAD Pro as shown in the Figure 3. Strut forces obtained from Plaxis (2D) for unit spacing are applied at Waller beam. Bending moment, shear fore and deflection of Waller beam and axial force of each strut were determined from STAAD Pro. model.

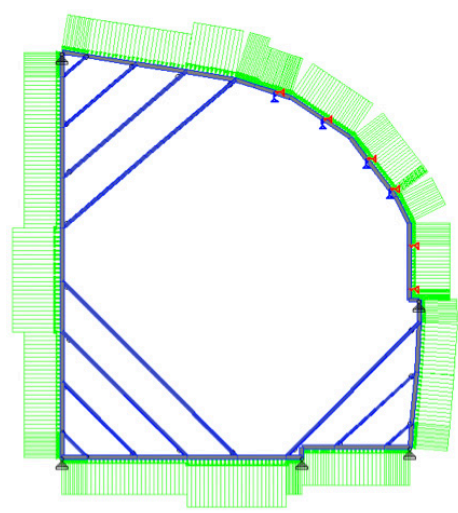

Figure 3: Structural model for Waller beam and struts

\section{PERFORMANCE MONITORING}

The FE analysis was performed to predict the stresses, strains and resulting deformations in the embedded retaining wall. The deformation results were used to establish estimates of performance that could be compared with field measurements, as a means of determining if the behavior of the wall was within what would be considered the normal range.

Qatar Construction Specifications 2014 (QCS, 2014) states, “A plan of monitoring shall be established (including necessary instruments and procedures) enabling the comparison of the actual behavior to the acceptable limits. The monitoring shall allow early detection of nonconformities, allowing enough time for corrective actions to be taken successfully" when setting criteria to enable monitoring during construction. QCS further specifies, for tunneling works, the contractor to submit detailed instrumentation plan, techniques and instrument types and also guidance on the zone of influence is provided. However, influence zone, monitoring techniques and instrument types to be used for monitoring of deep excavations are not explicit and clearly defined. In the absence of particular specifications, by the design consultant or owner, for the instrumentation and monitoring of deep excavations, the contractor usually proposes monitoring regime that is the bare minimum and may not enable the comparison of the actual behavior to the acceptable limits, as specified by QCS.

\subsection{Monitoring regime}

Optical survey was used to monitor embedded wall movements by the survey targets being mounted near the top of wall. The monitoring scheme used in this selected case is shown in Figure 4. Optical surveys may give reasonable results if they are performed carefully but the problem with optical surveys is that measurements can only be recorded at the location of survey points, as such this technique is not capable of measuring the deflections throughout the wall depth. Secondly, the optical survey is not able to capture 
early detection of induced ground movements due to deep excavation that would occur before the installation of survey targets.

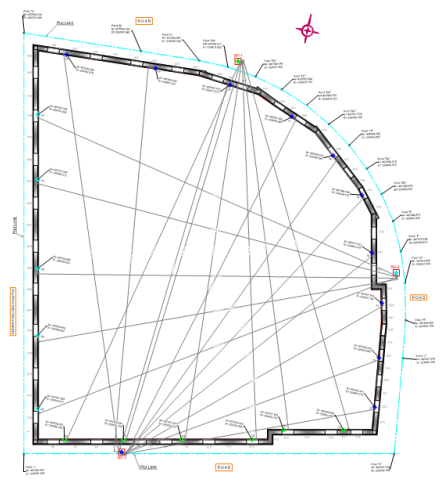

Figure 4: Monitoring regime

For monitoring of deep excavations, detailed instrumentation and monitoring plan should be established. Humza (2019) suggests defining zone of influence and review levels. Review levels are pre-determined values which are established by the designer as a control procedure for monitoring and checking the performance of the designed / impacted structure during excavation work. The review levels are comprised of Alert Levels (AL) and Work Suspension Levels (WSL) and these levels are proposed based on the prediction from the FE analyses. The review levels are set as:

Alert Level $=70 \%$ of design value.

Work Suspension Level $=100 \%$ of design value.

In general, more commonly used instruments for ground monitoring as well as to reveal the effects of excavation works on the existing buildings are inclinometers, extensometers, ground settlement markers, building settlement markers, tiltmeters and vibration monitors. However, for the deep shaft excavation advanced instrument types such as fiber optical sensors have been used (Schwamb et. al., 2014).

\subsection{Comparison of predicted and observed behavior}

Figure 5 illustrates the comparison between observed and predicted lateral wall movements using FEM models at the final excavation stage of three sections. The maximum lateral wall movements are $0.14 \% \mathrm{H}, 0.10 \% \mathrm{H}$ and $0.11 \% \mathrm{H}$ for section 1,2 and 3 respectively $(\mathrm{H}=$ depth of excavation). The predicted movements compare reasonably well with the observed magnitude at the points where survey targets were installed. However, the predicted magnitude of wall movements is higher at the excavation base, where the movements could not be captured by optical survey. At the base of excavation, predicted movements indicate bulging behaviour, which is well established phenomenon for the braced excavations (Clough \& O'Rourke, 1990). Moreover, the main factors responsible for the ground settlement trough behind the retaining wall are the magnitude and shape of deformation of a retaining wall $(\mathrm{Ou}, 2006)$. The optical survey technique may be used to measure a cantilevered deformation pattern such as produced in excavation with cantilever wall and also at the early construction stages 
before installation of struts as a back-up reference, However, this technique is unable to measure the bulging pattern of wall deformation near the excavation base at the final excavation stage. Therefore, an appropriate monitoring instrument such as inclinometer is recommended to use for performance monitoring of the embedded walls.
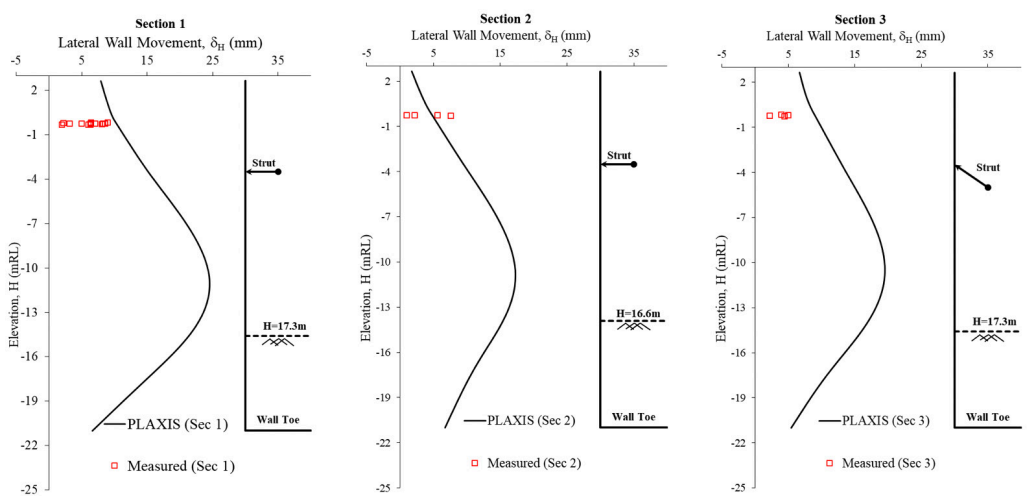

Figure 5: Comparison between observed and predicted lateral movements using PLAXIS

Figure 6 shows the predicted surface settlement using MC model. In general, its use leads to settlement troughs shallower and wider than those observed experimentally (Humza, 2010), signifying the limitation of the model in predicting surface settlement. For this project, surface settlement was not measured since no critical structures were present in the surroundings.

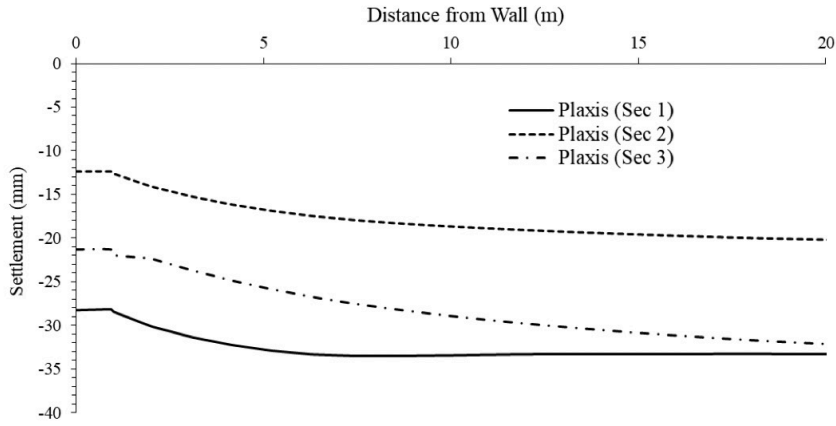

Figure 6: Predicted settlement by PLAXIS

\section{CONCLUSION}

This paper presents design methodology as a guideline to engineers for the stress and deformation analysis using finite element method for effective designing of embedded retaining wall supported by inclined and diagonal struts for deep excavation. The following points can be concluded:

- The finite element methods can be used effectively for the stress and deformation analysis not only to capture complexity of the interaction between the retaining structure and ground conditions in Qatar but also to establish a site-monitoring control system. The site-monitoring control system should then be implemented by chalking out a proper instrumentation program during construction.

- Although the predicted deflection behavior of diaphragm wall shows good agreement 
with observed behavior measured at the top of wall, but the monitoring technique commonly used in local industry is not capable of determining shape of lateral wall movements.

- In order to assess the performance of braced excavations, an appropriate monitoring technique and instrument type is recommended to use that is capable of measuring the deflection profile throughout the depth of embedded wall.

Based on this study, authors suggest design consultants and authorities to make performance monitoring of deep excavation a statutory compulsion and specify the type, quantity and monitoring frequency of an appropriate instrument such as inclinometers for the lateral wall deflection profile. This shall allow early detection of nonconformities, allowing enough time for corrective actions to be taken successfully especially for the deep excavation nearby existing buildings and structures.

\section{REFERENCES}

Adnan A.M. et. al. (2019). Diaphragm wall supported by ground anchors and inclined struts: A case study. International Journal of GEOMATE, Vol. 16, 57, 150-156.

Cavellier, C., Salatt, A. \& Heuze, Y., (1970). Geological description of the Qatar peninsula, Explanation of the 1/100,000 geological Maps of Qatar, Bureau de recherches geologiques et minieres, Paris, France.

Clough, G.W. \& O'Rourke, T.D. (1990). Construction induced movements of in-situ walls. Proceeding of ASCE Conference on Design and Performance of Earth Retaining Structures, ASCE Geotech. Spec. Publi. No. 25, New York, 439-470.

Fourniadis, I. (2010). Geotechnical characterization of the Simisma Limestone (Doha, Qatar), Geoenvironmental Engineering and Geotechnics: progress in Modeling and Application, GeoShanghai 2010, He Q and Shen SL (eds) ASCE, Reston, VA, USA, Geotechnical Special Publication no. 204, 273-278.

Humza M. et al. (2010). Numerical modeling of diaphragm wall behavior in Bangkok soil using Hardening Soil model. The 4th International Conference on Geotechnical Engineering and Soil Mechanics, Tehran, Iran 2010, Publication no. 660.

Humza M., (2019). Serviceability limit prediction, monitoring and performance of Open Cut Slope. Proceedings of 15th International Conference on Geotechnical Engineering, Lahore, Pakistan.

Ou, C. Y. (2006). Deep Excavation: Theory and Practice, Taylor and Francis. London.

Qatar Construction Specification (2014). Ministry of Municipality and Environment, Qatar.

Schwamb, T. et. al. (2014). Fibre Optic Monitoring of a deep circular excavation. Proceedings of Institution of Civil Engineers, ICE Geotechnical Engineering, Vol 167, issue GE2, 144-154. 